\title{
Design of Stormwater Particle Removal System for Small-Scale Urban Hydropower based on the Vortex and Coandă Effects
}

\author{
Norashikin Ahmad Kamal ${ }^{\# 1}$, Gooyong Lee*2, Sangmin Shin ${ }^{* 3}$ \& Heekyung Park*4 \\ \#Faculty of Civil Engineering, Univesiti Teknologi MARA, Shah Alam,40450, Selangor, Malaysia \\ 11norashikin7349@salam.uitm.edu.my/shikin230783@gmail.com \\ *Department of Civil and Environmental Engineering, \\ Korea Advanced Institute of Science and Technology (KAIST), Daejeon, Republic of Korea \\ 2bluewater0703@kaist@kaist.ac.kr \\ ${ }^{3}$ happy_sm@kaist.ac.kr \\ 4hkpark@kaist.edu
}

\begin{abstract}
Small hydropower systems are a future concept for urban regeneration development. Such a system should function properly under tropical conditions, where rainfall is especially abundant. To implement a small-scale urban hydropower system, a special design is needed to handle diverse sedimentary sizes and deposition characteristics of particles in stormwater, which if unattended may disrupt the functioning of turbine-generator components. Combining the effects of stormwater vortex and Coandă was previously suggested to enhance particulate removal efficiency. This paper was prepared based on this concept. The paper specifically aims to quantify the design parameters which are vital for a high removal efficiency system. These optimal design parameters are also presented in detail in this paper.
\end{abstract}

Keyword - Urban Hydropower System, Stormwater Infrastructure, Combination Effects

\section{INTRODUCTION}

A small hydropower system within stormwater infrastructure is technically feasible as part of the future urban regeneration concept [1],[2],[3],[4] and [5]. Previous studies have highlighted the need to modify the detention outlet to ensure constant flow rates for a more efficient small-scale urban hydropower system [5]. In this paper, stormwater infrastructure refers to a detention pond which could be used for developing small-scale urban hydropower.

Specific challenges to the implementation of small-scale urban hydropower systems include stormwater quality and flow fluctuation. In terms of stormwater quality, the infinite variety of sedimentary sizes and deposition characteristics complicate the design of a detention outlet. Stormwater particles range from coarse grains to silts, and are highly dependent on site topography. It is therefore necessary to design a new and unique system that can handle these stormwater particulate varieties. A clean stormwater source is needed for energy generation purposes to avoid problem on turbine erosion which may reduce the performance of energy generation. For example, in big hydropower system, treatments such as screen intake are used to filter large particles from entering the turbine and generator components.

Two theories about vortex and Coandă had been investigated in order to ensure the applicability of the effects for removing the particles in stormwater. These effects also may help cope with the fluctuation of water. Vortex effects had been applied in the hydrocyclone and may easily remove fine particles by using centrifugal force especially when the high velocity is observed [6],[7],[8],[9] and [10] Coandă effects had been well applied in aerodynamic design [11], hydropower [12] and stormwater system [13]. Coandă may help to remove light and coarse particles and could regulate the flow water based on its optimized slope condition. In referring of above challenges, one possible solution is to utilize combined effects of stormwater Coandă and vortex, which may not only solve particulate problems, but also stabilize stormwater flow rate. It nevertheless remains imperative to assure clean water source for a small-scale urban hydropower system.

The authors therefore proposed a new system designed based on the combined effects of vortex and Coandă, which should be in particular practical for tropical countries with high intensities of rainfall. The build-in technique for these combination effects is established after the detention outlet of urban stormwater infrastructure system. The paper specifically aims to quantify crucial design parameters that may the system efficiency. Several initial limitations considered included (1) the design shall be installed in a fully covered and paved area; and (2) a rainwater storage site or pond must already be available. One should also note that while stormwater particles in urban areas typically range from $50 \mu \mathrm{m}$ to $900 \mu \mathrm{m}$ ( [14],[9], [15] and [16]), the proposed design only works with fine particles ranging between $50 \mu \mathrm{m}$ and $250 \mu \mathrm{m}$. This is because coarser particles, making up about 40 to $60 \%$ of total stormwater, settle easily in the detention pond. Therefore, in the short term, 
fine particles $(50 \mu \mathrm{m}$ to $250 \mu \mathrm{m})$ are the major source of inefficiencies in the small-scale urban hydropower designs.

\section{Methodology}

\section{A. Design of the Experimental Setup}

Thorough literature reviews on flow pattern and performance efficiency of vortex and Coandă effects were carried out prior to the design of the experimental setup ( [7], [17], [12] and [13]). It was then clear that specific hydraulic conditions such as pressure head differences and inlet velocity openings must properly be quantified. The formulae of hydro cyclone components used to design vortex effects in this study are briefly summarized in Table 1.

TABLE 1. Detailed calculation design for each important component in hydrocyclone

\begin{tabular}{|c|c|c|c|}
\hline Components & Description & Formulae & Expected Results \\
\hline Inlet Velocity & $\begin{array}{l}\text { Fast inlet velocity is } \\
\text { needed to produce high } \\
\text { turbulent flow in the } \\
\text { hydrocyclone. This is } \\
\text { important for getting the } \\
\text { reasonable results of flow } \\
\text { patterns especially at the } \\
\text { centrifugal section of } \\
\text { hydrocyclone. }\end{array}$ & Qinflow $=2 \pi R L V_{r}$ & $\begin{array}{l}\text { Inlet velocity of the } \\
\text { hydrocyclone should be same } \\
\text { or maybe higher than the } \\
\text { velocity from Coandă effect. } \\
\text { So, expected range of inlet } \\
\text { velocity is around } 0.9 \text { to } 2 \mathrm{~m} / \mathrm{s} \\
\text { based on the flow equality } \\
\mathrm{AV}_{\text {Coandă }}=\mathrm{AV}_{\text {vortex }} \\
\text { *Detailed explanation of the } \\
\text { inlet velocity of hydrocyclone } \\
\text { had been compiled from a } \\
\text { thorough review of literature; } \\
\text { and it is dependent on the size } \\
\text { of the hydrocyclone }\end{array}$ \\
\hline $\begin{array}{l}\text { Separation } \\
\text { Efficiencies }\end{array}$ & $\begin{array}{l}\text { Normally it is also called a } \\
\text { function of particle size. In } \\
\text { this study efficiencies are } \\
\text { determined based on total and } \\
\text { solid balances. }\end{array}$ & $\begin{array}{l}\mathrm{E} 1=w_{o} \quad \mathrm{E} 2=w_{u} \\
\mathrm{E} 3=\mathrm{O} / \mathrm{F} \\
\mathrm{E} 4=\mathrm{O} w_{o} / \mathrm{F} w_{f} \\
\mathrm{E} 5=\mathrm{U} / \mathrm{F} \\
\mathrm{E} 6=\mathrm{U} w_{u} / \mathrm{F} w_{f} \\
\mathrm{E} 7=\mathrm{O} / \mathrm{U} \\
\mathrm{E} 8=\mathrm{O} w_{0} / \mathrm{U} w_{u} \\
* \mathrm{~F}=\text { Total mass } \\
\text { flows } \\
\mathrm{O}=\text { Outflow } \\
\mathrm{U}=\mathrm{Underflow} \\
w=\text { weight of solids } \\
* \text { expression until will } \\
\text { be } \\
\text { Liter/second(L/s) in }\end{array}$ & \\
\hline $\begin{array}{c}\text { Normal } \\
\text { Acceleration }\end{array}$ & $\begin{array}{l}\text { Based on velocity } \mathrm{u}_{\mathrm{i}} \text { of } \\
\text { incoming liquid and inner } \\
\text { diameter } \mathrm{D} \text { of the top } \\
\text { The design must ensure } \\
\text { that } \mathrm{a}>9.81 \mathrm{~m} / \mathrm{s} 2 \text { for the flow } \\
\text { to go upward and outflow. }\end{array}$ & $\begin{array}{l}\qquad a=\frac{w^{2}}{D \ell^{2}} \\
\text { Which } \mathrm{u}_{\mathrm{i}}=\text { incoming } \\
\text { liquid } \\
\quad \mathrm{D}=\text { inner diameter }\end{array}$ & $\begin{array}{l}\text { Inlet velocity range of } \\
0.9 \mathrm{~m} / \mathrm{s} \text { to } 2 \mathrm{~m} / \mathrm{s} \\
\text { Inner diameter is around } \\
0.075 \mathrm{~m} \\
\text { Range of } 30.9 \mathrm{~m} / \mathrm{s}^{2} \text { to } \\
152 \mathrm{~m} / \mathrm{s}^{2}>9.81 \mathrm{~m} / \mathrm{s}^{2}\end{array}$ \\
\hline
\end{tabular}

As such, an experimental setup was designed as shown in Figure 1. As depicted in Figures 1 and 2, the top of the circular section was used to screen for Coandă effects, while its bottom was used to drain treated water into the main container. One notes that how much the wedge wire was titled significantly affects efficiency of the Coandă screen. Figures $2 \mathrm{a}, \mathrm{b}$ and c illustrate the Coandă effect screen in detail. The hydraulic performance of the Coandă effect design was measured using Coandă effect software established by [18]. However, the software needed to be modified because of the different shape of Coandă effect used in this study. 


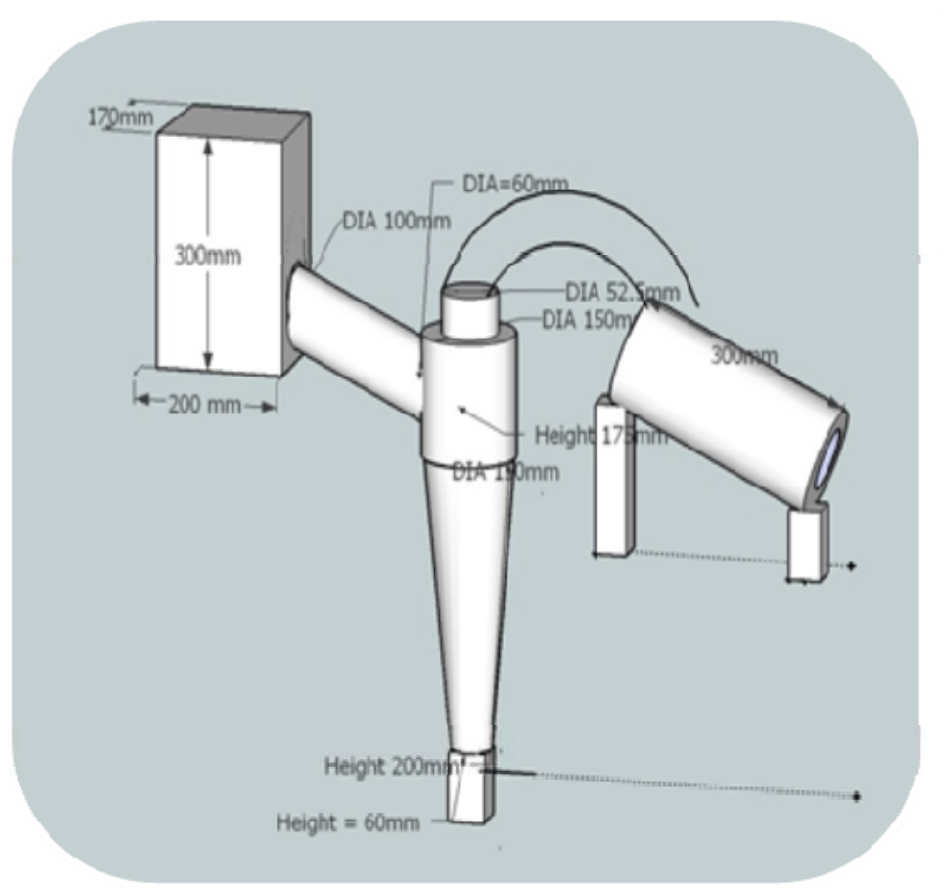

Fig. 1. Detail dimensions of the experimental setup to quantify the combination effects of vortex and coanda.
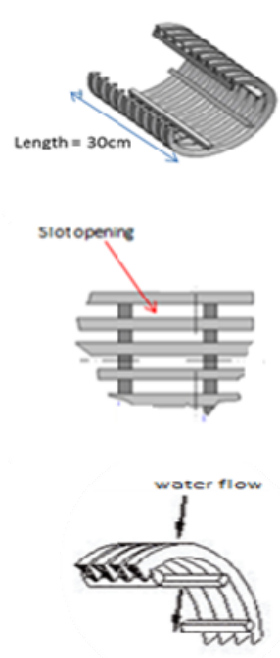

Fig. 2a) Internal (half surface only) of the screen

Fig. 2b) Detailed layout (surface view) of the screen

Fig. 2c) Direction of flow across the screen

\section{B. Experimental Work}

In order to determine the removal efficiency for these combination effects, detailed analysis of the selection of important design parameters must be conducted. 10 parameters have been selected as the important design parameters in the experimental work.

Equation 1 shows the 10 parameters selected based on dependencies from the list of important parameter. Equation 2 shows the basic design parameters from dimensional analysis. Dimensional analysis is conducted to reduce amount of the experiment time and to develop the basic design parameters which influence the removal efficiency of these combination techniques. Other than that, dimensional analysis also helps maintain dynamic similarity with real conditions at the field site.

$$
\begin{aligned}
\Delta \mathrm{C} & \left.=P_{s} ; C_{o} Q ; ; V_{i} ; \mu ; \rho ; d ; g ; W_{\text {slot }} S_{D} \quad \text { (Equation } 1\right) \\
\Delta \mathrm{C} & =\text { Change of Concentration } \\
P_{s} & =\text { Particle Size } \\
C_{o} & =\text { initial concentration } \\
Q & =Q_{\text {inflow }} \text { to the vortex section } \\
V_{i} & =\text { inlet velocity } \\
\mu & =\text { viscosity of water } \\
\rho & =\text { Density of water } \\
D & =\text { hydraulic diameter }=\text { inlet diameter of hydrocyclone } \\
G & =\text { gravity at accelerator plate of Coand } \breve{a} \\
W_{\text {slot }} & =\text { Width of slot } \\
S_{D} & =\text { Slope degree }
\end{aligned}
$$

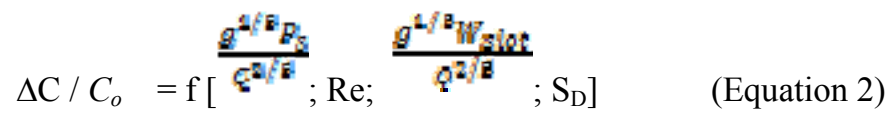

Equation 2 is used as the basis condition for conducting all the experiment cases. Total number of scenario based on the dimensionless design parameter for conducting all experiments was 81 cases. The experiment was conduct based on the scenario case number to examine the removal efficiency of stormwater particles. Relevant values of control parameters were obtained from references. Table 2 tabulates ranges of the control parameters used in this experiment. 
TABLE 2. Range of Control Parameters in the Experiment

\begin{tabular}{|c|c|c|}
\hline $\begin{array}{c}\text { Control } \\
\text { Parameter }\end{array}$ & Range & Important Value \\
\hline $\mathbf{Q}(\mathbf{L} / \mathbf{s})$ & $\begin{array}{c}0.5 \mathrm{~m}^{3} / \mathrm{s} \text { to } 15 \mathrm{~m}^{3} / \mathrm{s} \\
\text { Design in this study is based on similar kinematic design. } \\
\text { Scale down factor is } 1 / 10([10],[19] \&[20])\end{array}$ & $0.5 ; 1.0 ; 1.5$ \\
\hline $\mathbf{P}_{\mathbf{s}}(\boldsymbol{\mu m})$ & $50 \sim 900$ city area $[14-16]$ & $\begin{array}{c}\mathrm{P}_{\mathrm{s}}<100 ; 100<\mathrm{P}_{\mathrm{s}}<150 ; \\
150<\mathrm{P}_{\mathrm{s}}<250\end{array}$ \\
\hline $\mathbf{W}_{\mathbf{s}}(\mathbf{m m})$ & $0.5 \sim 1.5([12],[13] \&[18])$ & 0.5 \\
\hline $\mathbf{S}_{\mathbf{d}}$ & $10^{\circ} \sim 60^{\circ}([12] \&[18])$ & $15,30,45$ \\
\hline
\end{tabular}

Figure 3 shows the three main components of the experimental setup, namely detention storage, hydrocyclone for evaluation of vortex effects, and Coandă effect screen. Ranges of particle sizes used were $150 \mu \mathrm{m}$ $<\mathrm{P}_{\mathrm{s}}<250 \mu \mathrm{m} ; 100 \mu \mathrm{m}<\mathrm{P}_{\mathrm{s}}<150 \mu \mathrm{m}$; and $<100 \mu \mathrm{m}$, respectively. These different particulate sizes were chosen since they are the most difficult to settle in a real detention pond shortly after rainfall. These particles were first mixed with water to the required concentration and then poured into the detention storage tank. The valve was opened accordingly to yield the required flow rates of $0.5 \mathrm{~L} / \mathrm{s}, 1.0 \mathrm{~L} / \mathrm{s}$, and $1.5 \mathrm{~L} / \mathrm{s}$. Slot width for the Coandă screen was $0.5 \mathrm{~mm}$ as recommended in previous researchers for its particulate removal efficiency. Inclinations of the Coandă screen were adjustable between $15^{\circ}$ and $45^{\circ}$. Outflow volume and particulate concentrations of the treated water were later measured through a filtration test

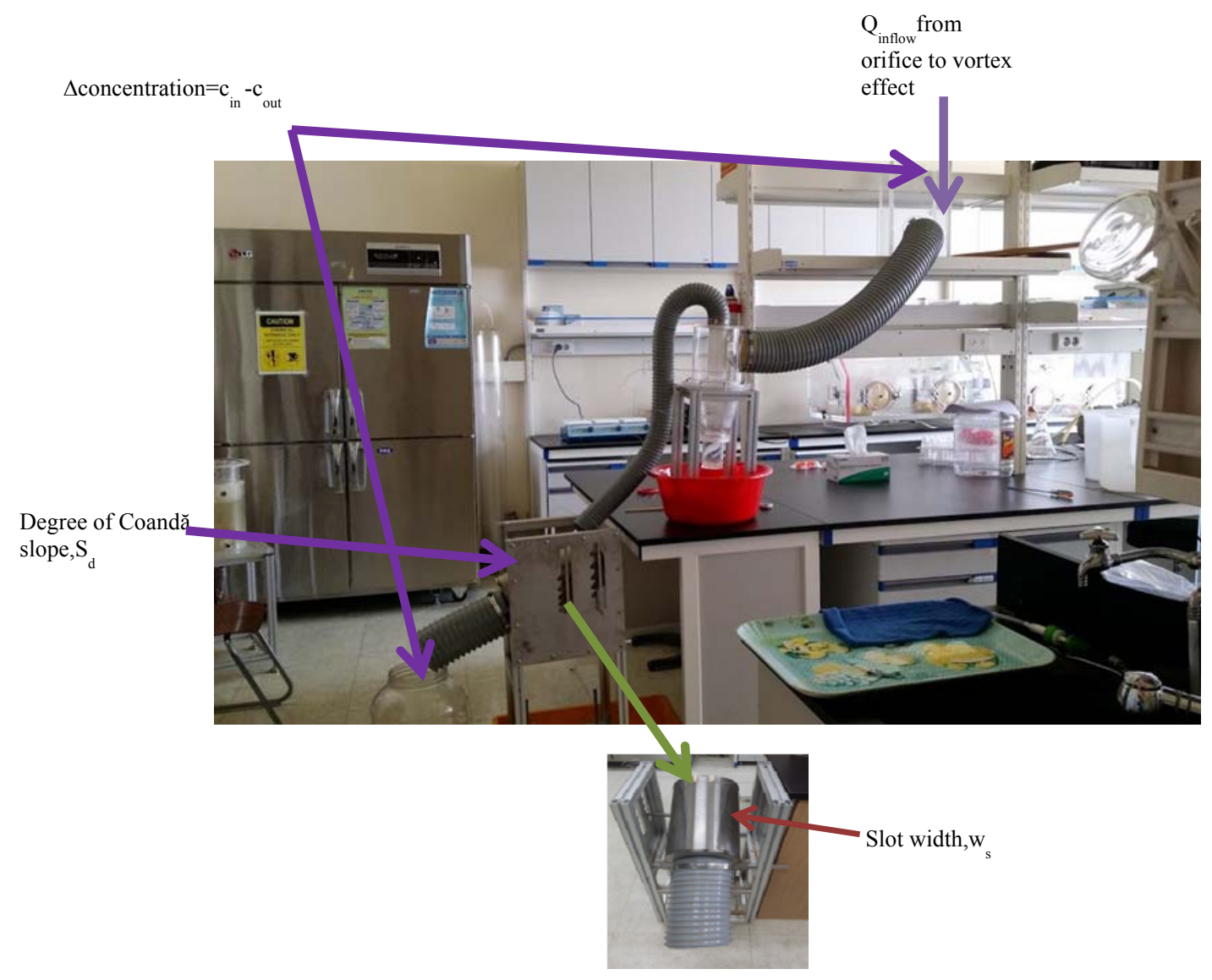

Fig. 3.The experimental setup to quantify the combination effects of vortex and Coandă for the small urban hydropower system. 


\section{III.RESULTS \& DISCUSSION}

Relying on the combined effects of vortex and Coandă is in essence relying on their differences in flow characteristics and particulate removal functions. A previous study on the vortex effects by Kwon et al., (2012) reported that removal efficiency of fine particles was greater by $3 \%$ to $10 \%$ when the flow rate of water (Q) was increased. The total removal efficiency was, however, only between $26.7 \%$ and $34.5 \%$. It can therefore be concluded that the inlet valve in the hydro-cyclone plays a major role in ensuring a high inlet velocity flow. Meanwhile, the Coandă screen was designed accordingly to the flow rate of water (Q), the targeted particulate sizes and their distributions within the area. Slot width and inclination of the Coandă effect screen also affects total particle removals. All these observations lead to a conclusion that substantial particulate removal efficiency may be recovered by combining the effects of vortex and Coandă. This paper presents the authors' findings for optimal design parameters for the high-efficiency particulate removal in the newly-proposed system.

The Q effect factor refers to the dependency of particle removal based on the flow rate of water (Q). Manipulation of different Qs is imperative, especially in the real scenario of system implementation. Figure 4, 5 and 6 depict the Q-effect factors based on three different inclinations of the Coandă effect screens. Overall, these figures show that a low flow rate of $0.5 \mathrm{~L} / \mathrm{s}$ consistently resulted in higher removal efficiencies than those of higher flow rates $(1.0$ and $1.5 \mathrm{~L} / \mathrm{s})$. It is also clear that finer particles require a low flow rate $(0.5 \mathrm{~L} / \mathrm{s})$ for a greater removal efficiency. The range of removal efficiency from the experiment with the 3 main Q's experiment is around $70 \%$ to $100 \%$ depending on the slope degree and particle size range. This indicates that the combination effects were sufficient to cope with different flow rates in the system, especially for practical implementation in an urban stormwater site.

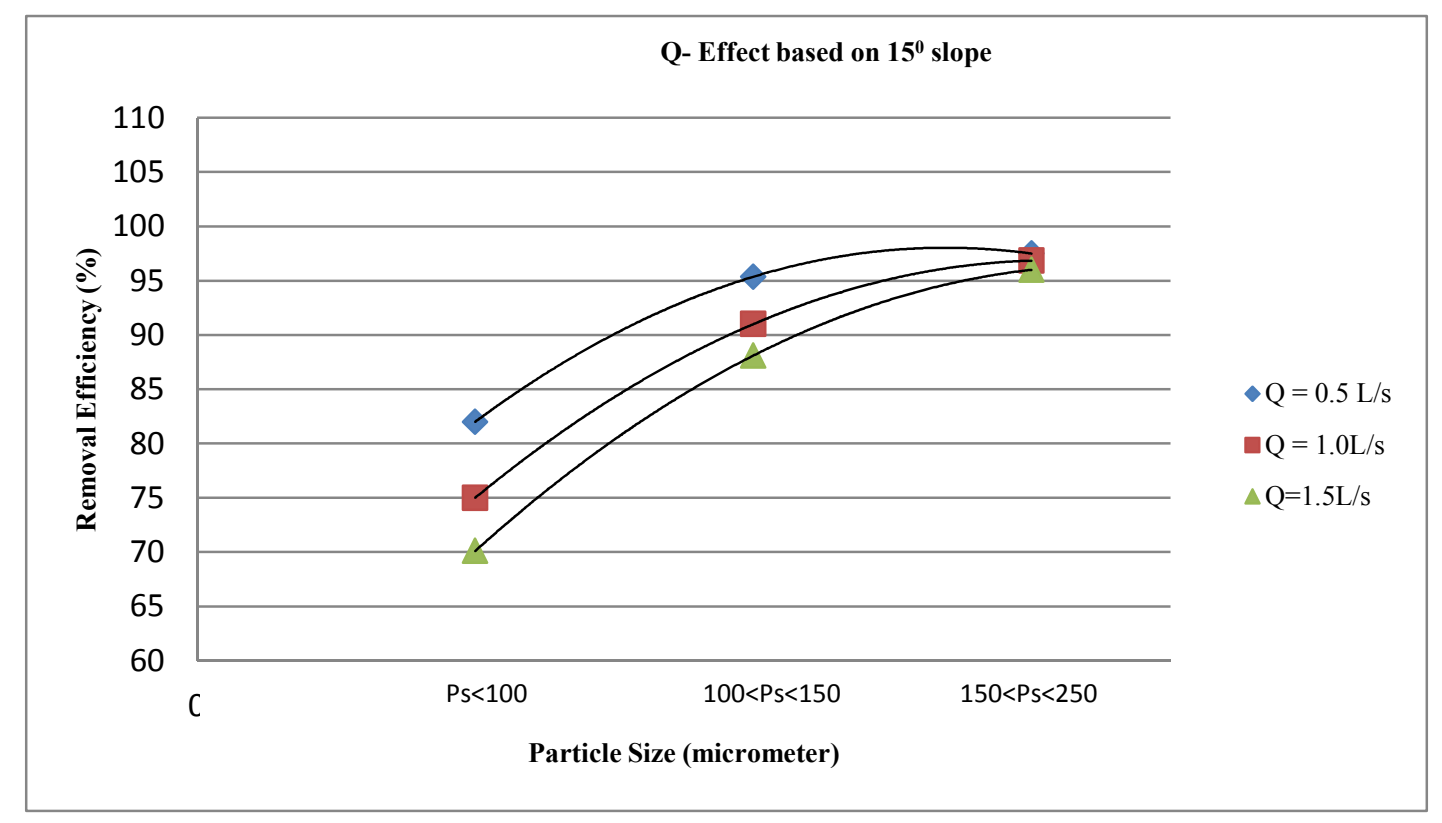

Fig.4. Effects of flow rate Q-effect on particulate removal efficiencies for the $15^{\circ}$ coanda screen 


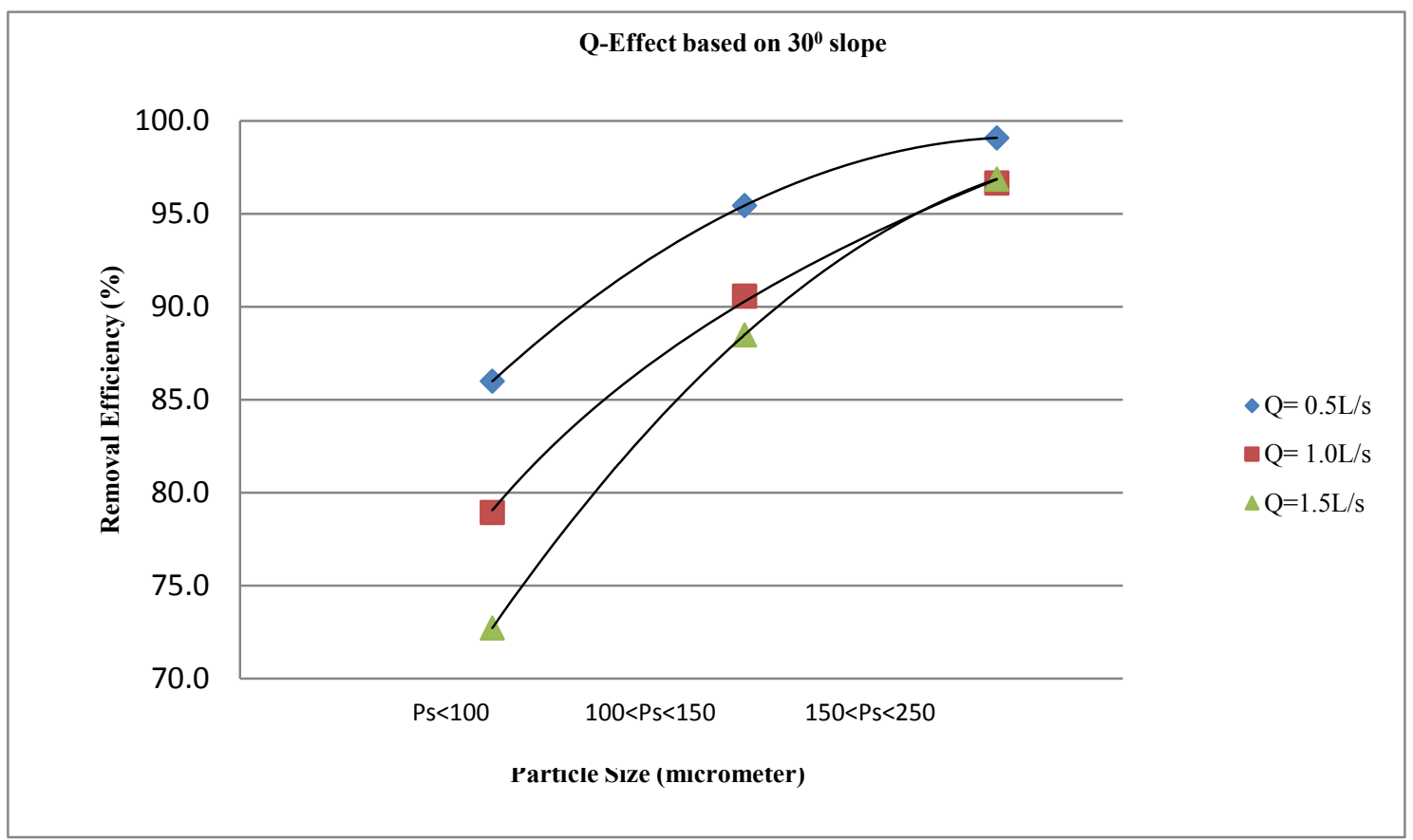

Fig.5. Effects of flow rate Q-effect on particulate removal efficiencies for the $30^{\circ}$ coanda screen

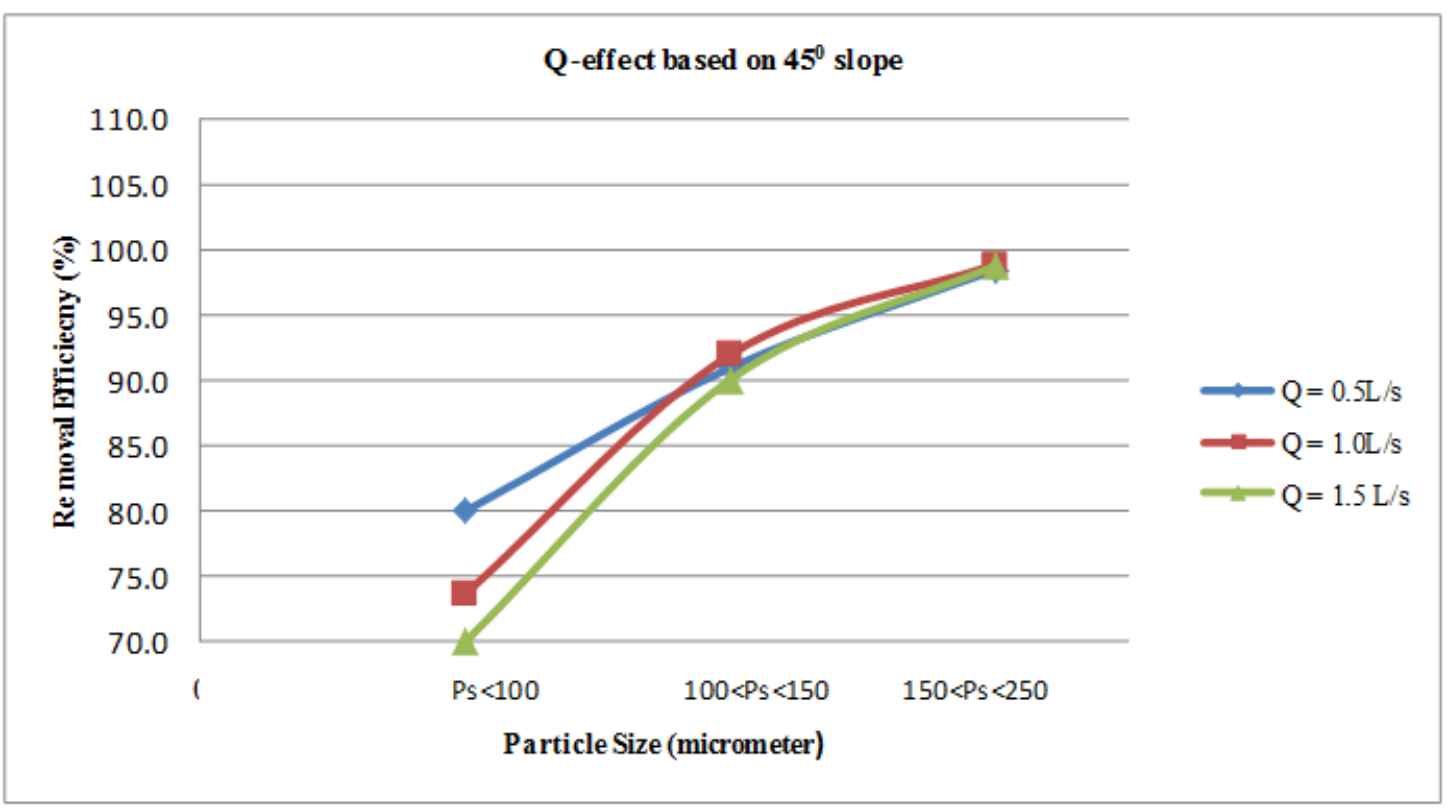

Fig.6. Effects of flow rate Q-effect on particulate removal efficiencies for the $45^{\circ}$ coanda screen

Figure 7 also clearly illustrates that a low flow rate (e.g. $0.5 \mathrm{~L} / \mathrm{s}$ ) consistently produces high removal efficiencies for all particulate sizes. Higher flow rates, nevertheless, also resulted in high removal efficiencies for coarse particles. This implies a positive correlation between removal efficiencies and particulate sizes, as well as water flow rates and Coandă screen inclinations. Wahl, (2001) in a Coandă effects study found that lower flow rate contributed to the greater removal efficiency; but Hsieh \& Rajamani, (1988); Quaian et al., (1989) \& Kwon et al., (2012) found that higher velocities in the vortex were contributed to the higher removal efficiency especially for the finest particle. The high inlet velocity in the vortex plays an important role in increase the centrifugal force of the swirling motion and the effluent flow was regulated in the Coandă screen. Therefore, through a combination of vortex and Coandă effects, the lower flow rate $(0.5 \mathrm{~L} / \mathrm{s})$ demonstrates greater removal efficiency. However, the difference of removal efficiency in between each coarser particle does not vary much compared to the finest particles. 
Coandă screen inclinations also leads to different removal rates for different particulate sizes, as depicted in Figure 8. High fine particulate removal efficiency was obtained with the $30^{\circ}$ slope. For coarse particles, effects of the Coandă screen inclinations on the particulate removal efficiencies are, however, not evident. It can therefore safely be deduced that the $30^{\circ}$ Coandă screen is quite optimal.

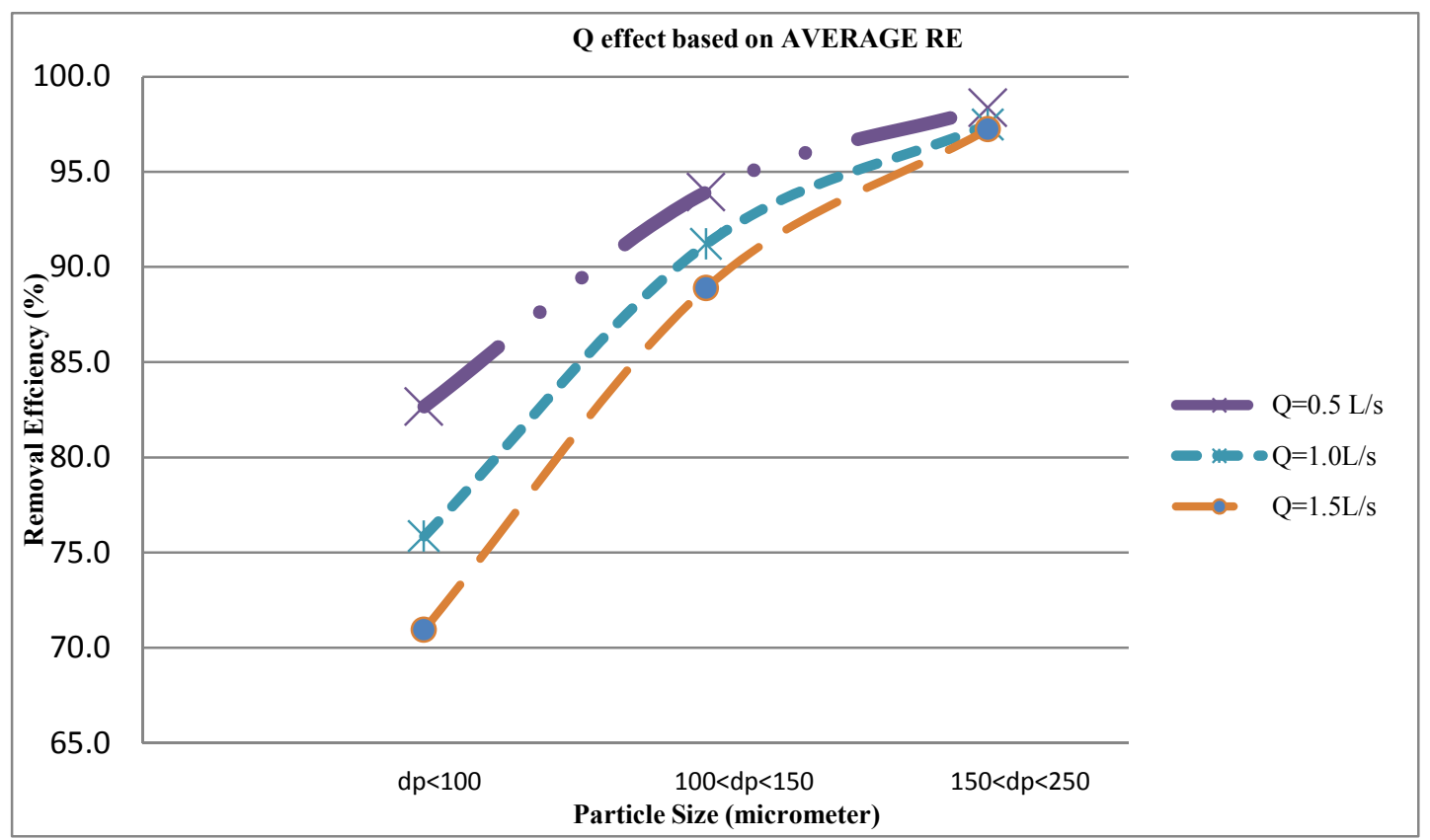

Figure 7: Impacts of flow rate Q-effect on the average removal efficiencies

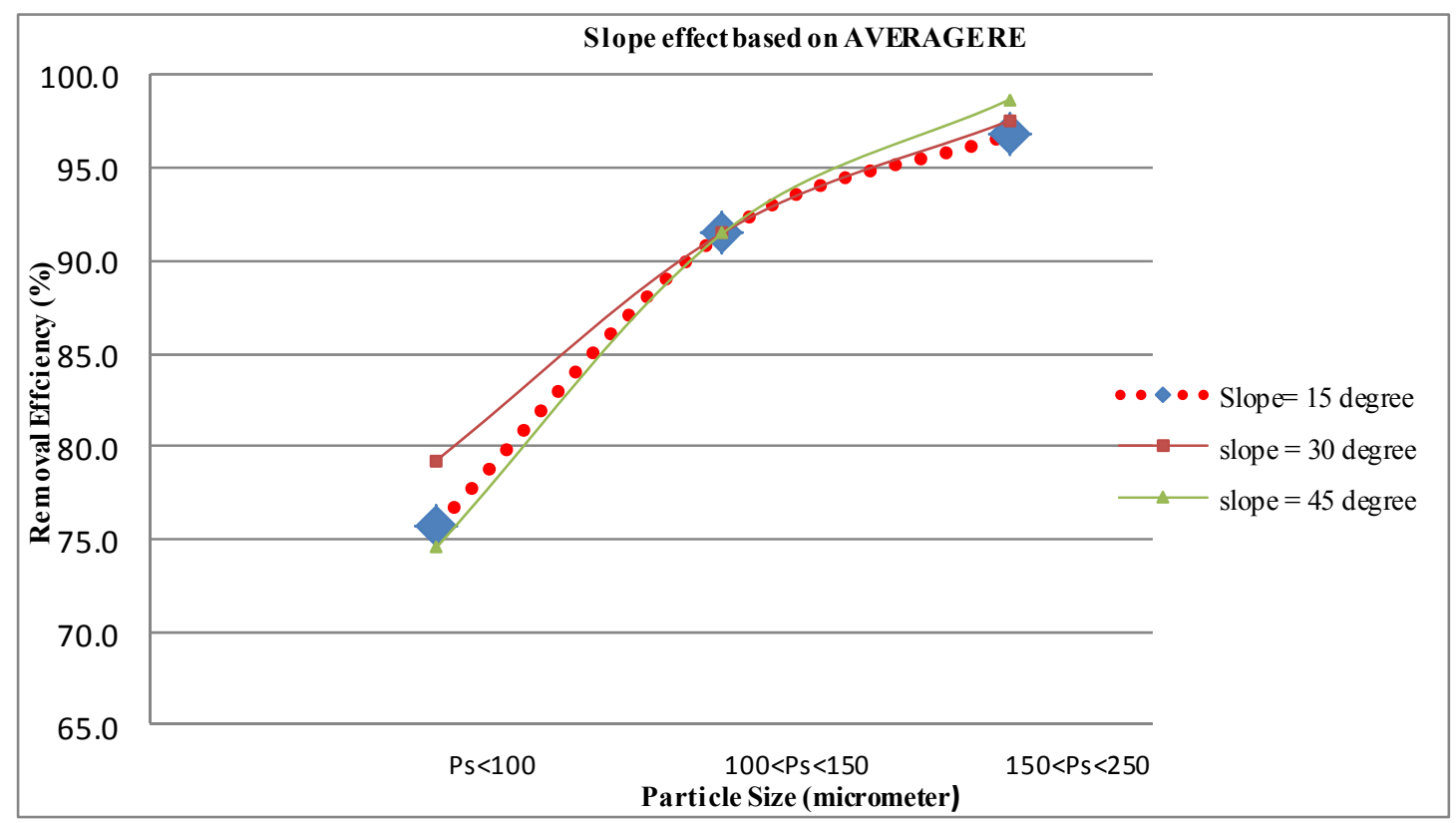

Figure 8: Effects of the Coandă screen slope on average removal efficiencies

To fully understand effects of water flow rate and Coandă screen inclination on particulate removal efficiencies, mixed particulate sizes were assumed instead, as plotted in Figure 9. It was discovered that a $30^{\circ}$ Coandă screen and $0.5 \mathrm{~L} / \mathrm{s}$ flow rate resulted in the highest recorded removal efficiency. These removal efficiencies slightly declined with increasing water flow rates for all Coandă screen slopes. 


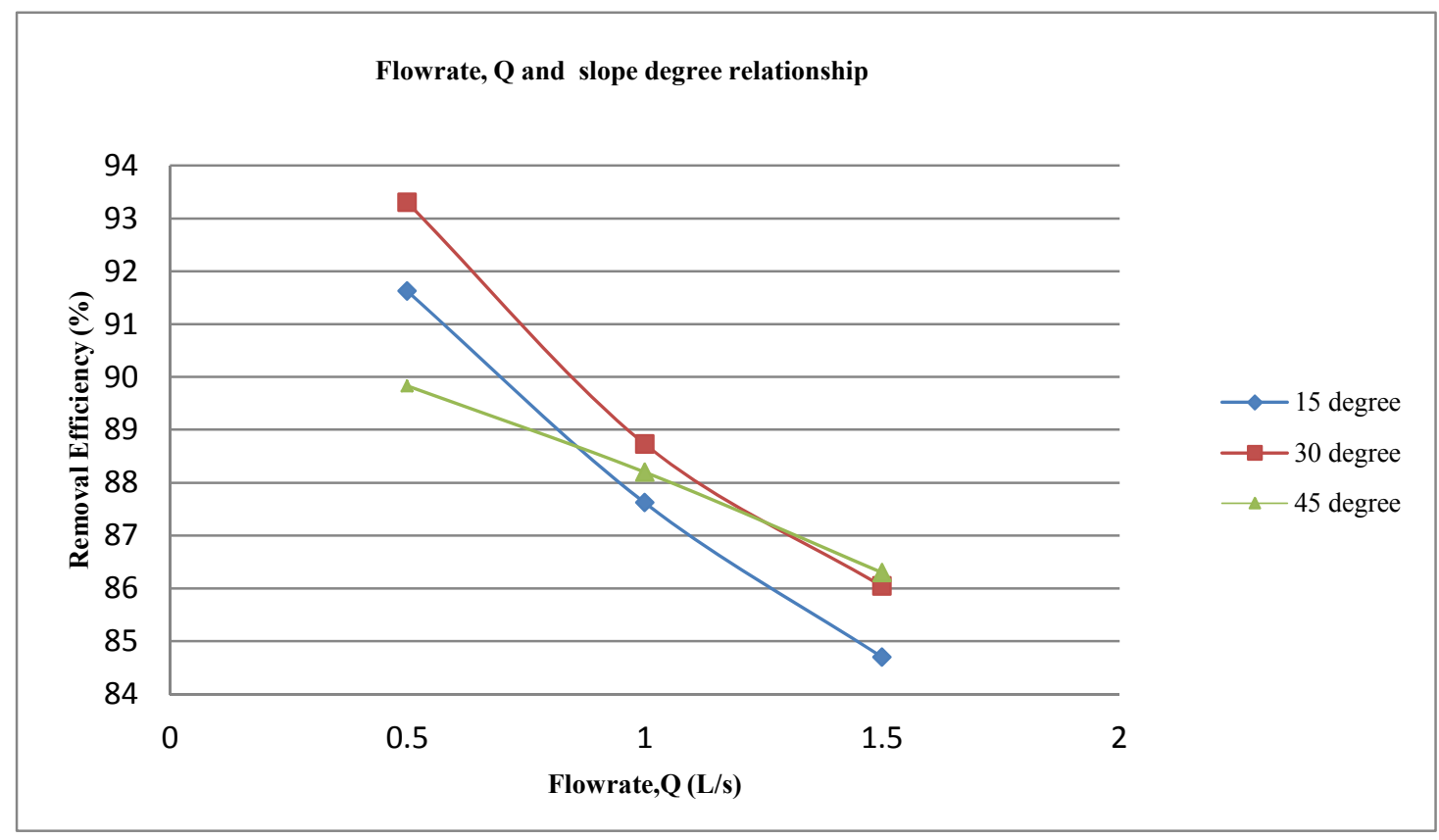

Fig.9.Relationship between flow rate and Coandă screen slope on average particulate removal efficiencies

\section{Conclusion}

This paper addresses significant design parameters based on vortex and Coandă effects which are relevant in stormwater treatment from detention pond outlets in order to develop a small hydropower system. 81 case scenarios were examined in order to evaluate the performance of particle removal. The system is only applicable for the tropical countries which receive abundance of rainfall and have detention pond as their stormwater infrastructure.

As shown in Section II, combining the effects of vortex and Coandă is quite effective in removing stormwater particles. In particular, flow pattern factors are significant in removing different particulate sizes. The optimal flow rate and Coandă screen inclination found in this study are quite practical for sites where stormwater oscillate for a period of time. This means high particulate removal efficiency can be achieved by combining the vortex and Coandă effects for any range of stormwater flow rate.

In the future, the authors intend to investigate the cost efficiency of developing a real small-scale urban hydropower system. The examination of cost efficiency results will be useful in replicating the system in the other cities and areas.

\section{ACKNOWLEDGEMENT}

This study is part of doctoral work of first author at Department of Civil and Environmental Engineering, KAIST. The research is fully supported by "Brain Korea 21" from the Korea Ministry of Education and by a grant (07-UR-B04) from the High-tech Urban Development Program funded by Ministry of Land, Transport and Maritime Affairs and the LESTARI fund (0014/2016) from Universiti Teknologi MARA, Malaysia.

\section{REFERENCES}

[1] Y. Li, Y.Tang, and D.Li, "Hydroelectric Potential of Stormwater Runoff from The University of British Columbia's Vancouver Campus," in British Columbia: CAWQ Western Regional Symposium 2006.

[2] B. Tim, and B.Robert,"Hydroelectric Feasibility Study :- An Assessment of the Feasibility of Generating Electric Power using Urban Stormwatre in Oregon City," Oregon: Oregon Institute of Technology.2009.

[3] H.M. Ramos, K.N. Kenov, and B.Pillet,"Stormwater Storage Pond Configurations for Hydropower Solutions: Adaptation and Optimization,”Journal of Sustainable Development, 5(No. 8), 27-42. 2012.

[4] A. Chang, J. Keating, S. Kwekkeboom, and N. Volikhovska, "Stormwater Management Options." University of British Columbia: UBC SEEDS. 2012.

[5] N.A. Kamal, H.Park, and S.Shin, "Assessing the Viability of Micro Hydropower Generation from the Storm Water Flow of the Detention Outlet in an Urban Area." Journal of Water Science \&Technology: Water Supply. doi:10.2166/ws.2014.022. 2014.

[6] A.M.Binnie, and G.A.Hookings," Laboratory Experiment on Whirlpools," Proceeding Royal Society, vol 194, pp 398-415.1948.

[7] K.T. Hsieh, and K.Rajamani.K., "Phenomenological model of the hydrocyclone - model development and verification for single-phase flow.” International Journal of Mineral Processing, 22(1-4), pp223-237.1988.

[8] L. Quaian, D.Changlie, X.Jirun, L.Yu and X.Guangai, "Comparison of the Performance of Water Sealed and Commercial Hydrocyclone. "International Journal of Mineral Process, 25, 297-310. 1989

[9] G. Zhu, J.L. Liow, and A. Neely, “ Computational Study of Centrifugal Instabilities in a Microsized Hydrocyclone.” Chemeca 2011, 506-515. 2011 
[10] K.H. Kwon, S.W. Kim, L.H. Kim, J.H. Kim, S.Lee, \& K.S. Min,’Particle removal properties of stormwater runoff with a lab scale vortex separator. Desalination and Water Treatment,pp 349-353.2012

[11] M.F. Djojodohardjo, M.F. AbdulHamid, S. Basri, F.I. Romli, and A.L.A. Abdul Majid.” Numerical Simulation and analysis of Coandă Effect Circulation Control for Wind Turbine Application Considerations.” IIUM Engineering Journal, pp19-42. 2011.

[12] T.L. Wahl, Hydraulic Performance of Coandă Effect Screens. Journal of Hydraulic Engineering, pp 480-488.2001.

[13] S.E. Esmond, L. Quinn, and R.K. Weir, Patent No. US 7805890B2. US.

[14] A.A. Ghani, H.M. Azamathulla, T.L. Lau,C.H. Ravikanth, N.A. Zakaria,N.A., C.S.Leow, \& M.A.M. Yusof.,"Flow pattern and hydraulic performance of the REDAC Gross Pollutant Trap." Flow Measurement and Instrumentation, 215 - 224. 2011

[15] H.J.B. Charles, T.L. Lau, and A.A. Ghani, 2013. "Sediment Size and Deposition Characteristics in Malaysian Urban Concrete Drains - A Case Study of Kuching City.” Urban Water Journal, 1-17. 2013

[16] M.F. Chow, Z.Yusop, and I. Abustan, "Relationship between sediment buildup characteristics and antecedent dry days on diferent urban road surfaces in Malaysia. "Urban Water Journal, 1-9. 2013.

[17] F.Concha, "Flow pattern in Hydrocyclones." KONA, 97-132. 2007.

[18] T.L.Wahl, "Coandă Effect Screen Research,"[Online] US Department of the Interior (Bureau of Reclamation): http://www.usbr.gov/pmts/hydraulics_lab/twahl/Coandă/. 2013

[19] R.M. Alkhaddar, C.H. Cheong, D.A. Phipps, R. Andoh, A.James, and P.Higgins," The development of a mathematical model for the prediction of the residence time distribution of the residence time distribution of a hydrodynamic vortex separator." 4th International Conference on Innovative Technologies in Urban Drainage (NOVATECH) (pp. 835-842). Lyon-Villeurbanne: The International Water Association (IWA). 2001.

[20] D. Pandya, "A Low Cost Micro Scale Cyclone Separator Design and Computational Fluid Dynamic Analysis." Arlington: The University of Texas. 2010.

\section{AUTHOR PROFILE}
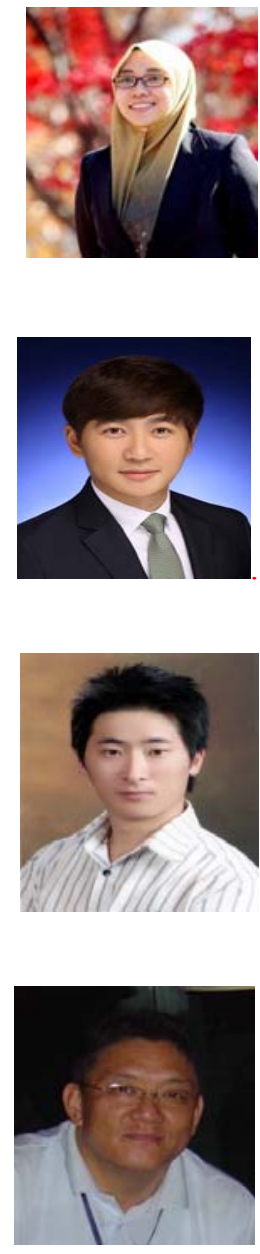

Norashikin Ahmad Kamal currently is working as a Senior Lecturer at Universiti Teknologi MARA,Malaysia. She graduated her doctoral study from Korea Advanced Institute of Science and Technology (KAIST) on 2015. Her research interest and focus is in the environmental engineering and urban water infrastructure system. She has been involved with projects in related with environmental and water managements sectors in South Korea and Malaysia.

Gooyong Lee was born in South Korea, 1980. He earned a bachelor's degree in Environmental Engineering at Yonsei University, South Korea, and finished the Master and PhD course at KAIST. Currently, he is a Research Fellow at the University of Malaya. His research focuses on the field of wastewater treatment and water resource management

Sangmin Shin currently is working at the University of Utah, USA as a postdoctoral researcher and was granted a Ph. D. degree at Korea Advanced Institute of Science and Technology (KAIST). He has been involved in many international and domestic water and disaster management projects. His major research areas include urban infrastructure system and water resources management for resiliently coping with disasters and their uncertainty.

Heekyung Park (Corresponding Author) is currently a Professor at Department of Civil and Environmental Engineering, Korea Advanced Institute of Science and Technology (KAIST). His major field is in the Urban and Green Engineering, Urban Infrastructure Management, Integrated Water Management, Environmental Systems Engineering. He has been involved in many international and local water projects in respect to the environmental engineering aspect, urban and green engineering development. 